\title{
INTEGRATING ECONOMIC AND ENVIRONMENTAL INDICATORS IN THE ASSESSMENT OF DESERTIFICATION RISK: A CASE STUDY
}

\author{
L. SALVATI ${ }^{1 *}-$ M. ZITTI $^{2}-$ T. CECCARELLI ${ }^{2}$

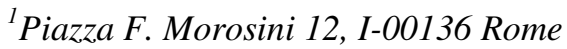 \\ ${ }^{2}$ CRA - Ufficio Centrale di Ecologia Agraria, Via del Caravita 7a, I-00186 Rome \\ e-mail:bayes00@yahoo.it
}

(Received $28^{\text {th }}$ February; accepted $23^{\text {th }}$ August 2007)

\begin{abstract}
Desertification involves many countries featuring different ecological, economic, and social conditions. In Mediterranean Europe, high human pressure, economic development, and climatic changes combine to produce land consumption, soil erosion, salinization, and fire risk, all considered as key factors to start desertification processes. For many years the term desertification has been strictly associated to geo-physical conditions, but in very complex ecosystems the study of the interaction of physical patterns with population and social characteristics is necessary to better delineate areas at risk. The aims of this paper are therefore (i) to review recent findings in term of desertification processes and risk assessment in the Mediterranean basin, (ii) to illustrate a simplified model in which social and economic variables may significantly accelerate land degradation leading to desertification, (iii) to suggest a set of demographic, economic, and institutional indicators suitable to contribute to the assessment of desertification risk in the Mediterranean basin, (iv) to built a synthetic index based on a multivariate approach and, finally, (v) to compare such index with a standard index of desertification risk only referring to geo-physical conditions. As a conclusion, new findings to be achieved in the context of human impact on environment as an original contribution to the study of desertification were delineated.
\end{abstract}

Keywords: desertification risk, indicators, demography, economy, Italy

\section{Introduction}

Desertification is a complex phenomenon which reduces the soil fertility involving ecological and economic processes that characterise the environment at different geographic scale [1]. The most widely accepted definition of desertification is the one given by the United Nation Convention:. It defines desertification as 'land degradation in arid, semi-arid and dry sub-humid areas resulting from various factors, including climatic variations and human activities' [2]. The term desertification was generally associated to geo-physical conditions (e.g. soil, slope, vegetation cover) coupled with drought features [3] and water availability [4], but in Mediterranean land the study of the interaction of physical patterns with population dynamics is necessary to better delineate areas at risk [5]. In fact, desertification impacts on the social, economic, and agricultural activities, and it is perceived as an ensemble of disasters affecting drylands, without a clear understanding of the involved processes [6]. The complexity of this phenomenon represents a limitation for the scientific approach and for the development of efficient action plans [7]. However, the interest for these problems was renewed in the last years, also considering the role of man in the way which external forces such as market, demography, tourism, and agricultural policies, influence the society-resource system [8].

The heterogeneity of cause-effects relationships and the interlinkages between desertification factors and human activities prevent to find an efficient methodology to evaluate the desertification process state [9]. Considering the multiplicity of statistical 
sources used in geographical studies it is hard to provide sound information on desertification trends also in more developed countries. In fact, desertification risk has been rapidly increased in Mediterranean Europe where human pressure, climatic changes and intensive economic development combine to produce soil degradation and erosion, as well as salinization and fire risk, all considered as key factors to start desertification processes [10]. Moreover, technological advancement, industrialisation of agriculture, and subsidy policies have accelerated the rate of land degradation during the last 50 years in environmental sensitive areas [11].

In this paper, indicators suitable to assess desertification risk in the Mediterranean basin were discussed with a special emphasis on demographic and economic aspects, providing key examples from Italy at both national and regional scales [12]. New findings to be achieved in the context of human impact on environment were also delineated as an original contribution to the study of desertification.

\section{Logical framework and social indicators}

\section{Desertification risk and human pressure: a scheme for the Mediterranean basin}

The causes of desertification may be split into two categories: natural and anthropogenic. The history of desertification in the Mediterranean actually follows the course of evolution of these two groups of causes and of their interactions. In fact, a severe decline of land's productivity, which will result in the desertification of an area, requires a conjunction of different social circumstances [13].

However, while desertification in the Mediterranean does not occur without irrational human activity, there are many cases where man's interference with nature has produced new socio-ecological systems that contribute to his welfare more than the natural ones. Such a case is the sustainable agriculture, which may have, through the ages, decreased biodiversity but it has provided livelihood for a greater number of inhabitants than the natural system [2]. A simplified model to describe social causes and consequences of drought and desertification in the Mediterranean basin could be improved (Fig. 1) according to the findings gathered in recent studies [7, 8, 14, 15].

The more typical causes incrementing desertification risk included both concentration of population and economic activity in coastal areas as a result of urban growth, internal migration, tourism and intensive agriculture, strictly associated with unsuitable exploitation of water resources, as well as crisis condition in traditional/marginal agriculture systems associated with land abandonment by rural populations and consequent deterioration of soil and water conservation structures especially in sloping areas $[4,13,16]$.

\section{Demographic and economic indicators of desertification risk}

The establishment of a system of information is vital in order to accurately assess the processes that lead to desertification and exacerbate the impact of droughts [3, 17]. In very complex ecosystems like Mediterranean land the study of the interaction of physical patterns with population characteristics is necessary to better delineate areas at risk [9]. Social and economic processes are difficult to assess at a low geographic scale. However, such processes are universally acknowledged to be important. As an example, socio-economic factors are known to influence the ways in which a territory's production bases are affected and how quality of life there is jeopardized by the 
extension of poverty, but very few studies have ventured to translate these processes into numerical values and still fewer have attempted to link them with other environmental indicators $[1,2,6,9]$.

Indicators are especially useful when they successfully link to improve knowledge of a complex and multidimensional phenomenon. The general framework used to assess desertification risk may be assigned to an ESA (Environmental Sensitivity Areas) procedure, developed in the framework of the MEDALUS research project [8]. In this model, different dimensions (climate, soil, vegetation, erosion) described by some key indicators (rainfall, slope, soil depth, etc.) produce a general risk index calculated as their geometric mean [18]. By using Geographic Information Systems, it is possible to produce high-resolution ESA maps (e.g., at the commune level).

In our opinion, low social variables are generally included in ESA procedures. For example, examining the Italian experience in terms of desertification risk assessment [15], the more wide effort to produce reliable estimations of the surface at risk occurred in the last ten years and produced more than twenty maps (both at national and regional level). Among such works, demographic indicators as population density and demographic variation over a decade were considered in only two maps (both at national level), while urban sprawling, elderly index, illiteracy index, retirement index as well as employed index were included in only one map (at regional level).

A panel of social and economic indicators should be promptly used in the cartographic evaluation of the desertification risk through ESA procedure [19]. The candidate indicators should be: (i) easily computed at the highest spatial resolution possible (e.g. municipalities or, better, census section), (ii) available at least each ten years (e.g., from national surveys), and (iii) recognisable as key descriptors in the fields reported in the logical framework (i.e., demography, agriculture, industry, tourism).

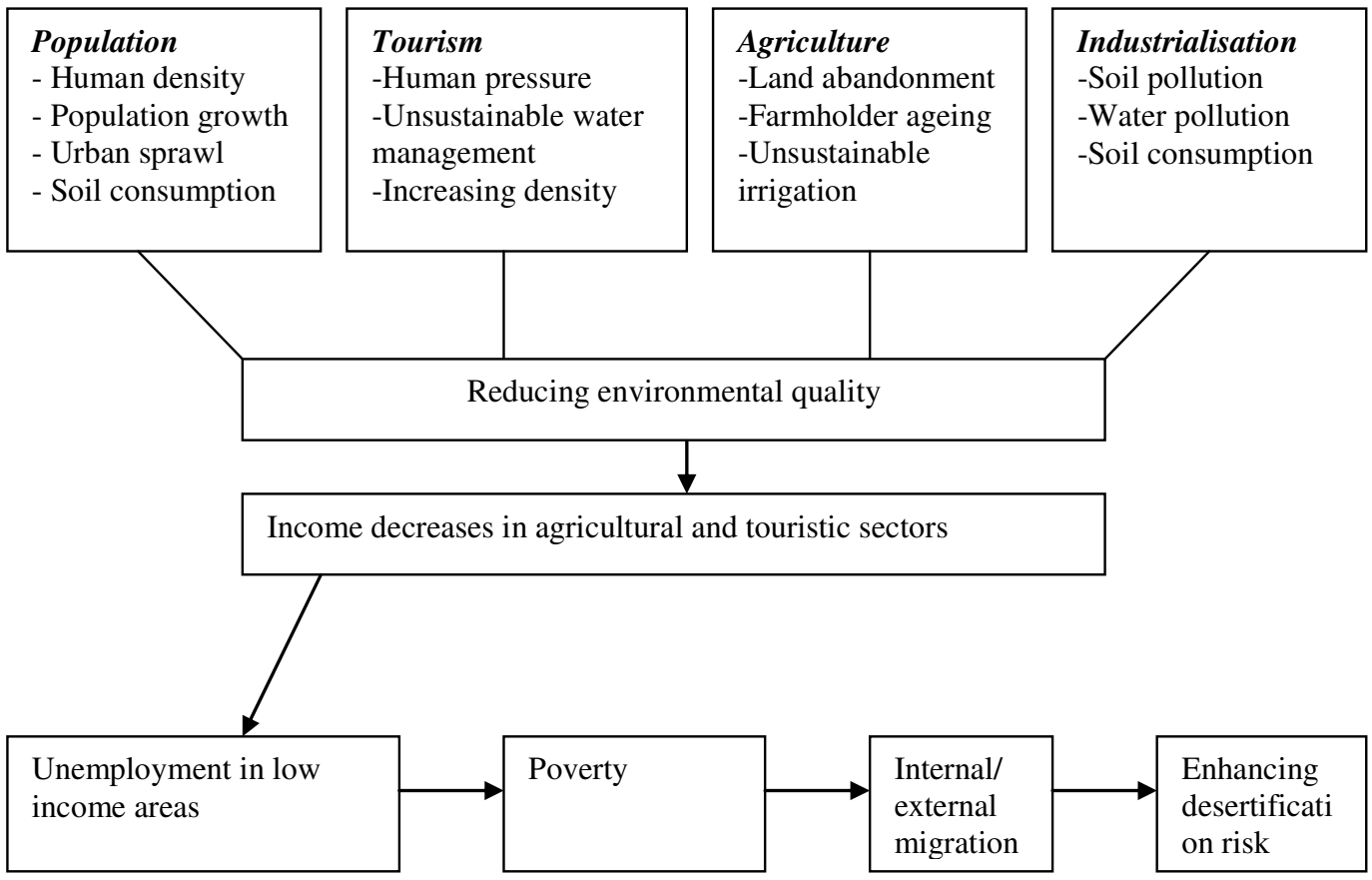

Figure 1. Anthropogenic factors affecting desertification risk and possible social consequences of land degradation 


\section{Results from a case study}

\section{Human pressure and demographic trend in Italy: a key example}

Taken as a leading factor of environmental degradation, human pressure has been enormously intensified during the last 50 years so that there are no remaining pure natural ecosystems in the Mediterranean Europe today [20]. An exponential increase in population has been taking place during the last century, with differential trends between coastal areas and marginal hilly and mountain areas far from the sea. The population growth in coastal municipalities, in common with all Mediterranean coasts, was remarkable and the divergence between population of the cities and the rest of regions is widening [6]. The decline of inland areas accentuates dichotomy between coast and the interior as far as services, quality of human potential and job opportunities are concerned [21].

Taking as an example the dynamics of Italian population during the last century, a wide population increase occurred along the whole coastal and lowland areas with the most exciting cases depicted by river Po plain, Tuscany and Latium Maremma, the whole Apulia, Sardinia and part of Sicily (Table 1). Apart from the Po plain, note that all the other zones are at risk of desertification. Grouping the Italian municipalities by altimetric zones, the differences in population size is greater in internal mountain zones (with a mean decrease of $73 \%$ ), but the higher population increase by decades (from 1921 to 2001) was observed in coastal areas, both lowlands and hilly ones, which are more sensitive to land degradation. Moreover, the maximum population increase was observed along the coasts and in hilly areas, while the greatest decrease, averaging $27 \%$ per decade, was measured in the municipalities from the internal mountains (Fig. 2).

Table 1. Population dynamics (average figures from commune data, 1921-2001) in Italy

\begin{tabular}{cccc}
\hline Altimetric regions & $\begin{array}{c}\text { Difference } \\
\mathbf{1 9 2 1 - 2 0 0 1}(\boldsymbol{\%})\end{array}$ & $\begin{array}{c}\text { Maximum population } \\
\text { increase by decade }(\boldsymbol{\%})\end{array}$ & $\begin{array}{c}\text { Maximum population decrease } \\
\text { by decade (\%) }\end{array}$ \\
\hline Internal mountain & -73 & 13 & -27 \\
Internal hilly areas & -11 & 16 & -21 \\
Coastal mountain & -4 & 19 & -18 \\
Coastal hilly areas & 29 & 22 & -14 \\
Lowlands & 22 & 19 & -13 \\
\hline
\end{tabular}
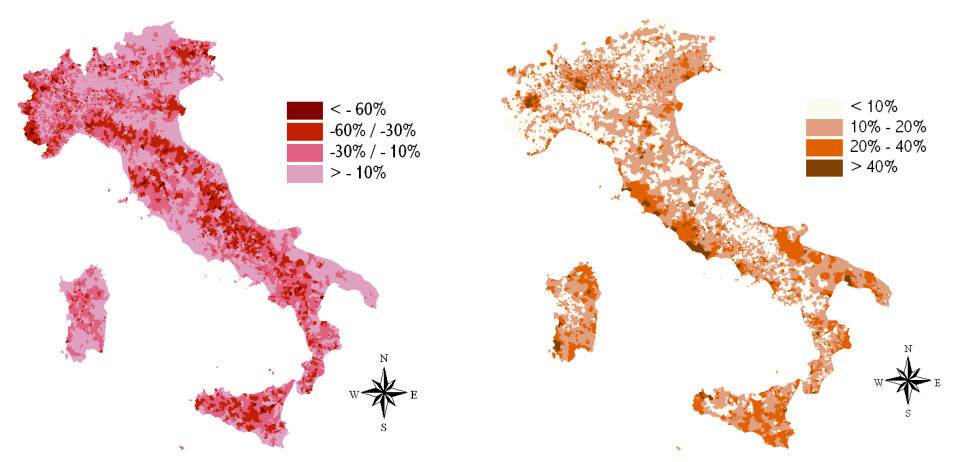

Figure 2. Difference in the population density between 1921 and 2001 at the commune level (maximum percent decrease (left) and increase (right) over a decade) 
Population increase has a direct consequence in the soil sealing by human expansion into productive lands, which has acquired high rates in the recent years [8]. Loss of agricultural land, degradation of high-quality soils, increase of fire risk, loss of seminatural vegetation, as well as salinization of groundwater are well documented with a marked relationship with the urbanisation phenomena [22]. The industrialisation and mechanisation of agriculture poses a question about the long-term sustainability of this human activity [23]. Moreover, the tourist influx in sensitive areas has become a problem since it promotes urban expansion to the expense of natural landscapes and contributes to the overexploitation of the water resources [3]. The pressure of tourism in coastal areas has exerted a significant impact on the environment, especially with respect to land-use patterns and on the local community. For example, unplanned urban expansion has resulted in the lack of even basic services such as water supply [24].

The abandonment of marginal agricultural lands may represents one of the consequences of an unbalanced population dynamics between internal and coastal areas as it had been brought by man to an unstable equilibrium [1]. In many cases, these are lands on sloping terrain, which were protected by erosion control structures and practices. Protection ceases and erosion accelerates when they are abandoned. Land abandonment started during the 1950s due to industrialisation of southern Europe countries, the increase in the cost of cultivation, the decrease of profits and the changes in the trade regulation among the countries. By 1990 between 10 and 20 percent of agricultural land in the Mediterranean countries was abandoned [13]. Whether an abandoned agricultural land will move towards recovery or desertification depends on the state of the land at the time of abandonment and on what follows afterwards [22]. For example, if intensive grazing follows good agriculture practices due to land abandonment, desertification may proceed, especially on sloping lands more sensitive to soil loss [1].

Human abuse or misuse of land seems to be an important cause of desertification. In what measure human related factors induce desertification and which human activities can have an impact on land degradation is not completely clear yet. However, these phenomena are moulded by socio-economic elements, such as the nature of property rights on land, the nature of governing institutions, cultural and family traditions, as well as demographic factors, such as population density [12]. In fact, desertification may generate political and institutional conflicts due to the increasing resource scarcity and poorly defined environmental entitlements [25].

As an extreme social consequence of desertification, migration movements may take place in reaction to increasing discrepancies between carrying capacity and population density in regions affected by land degradation and desertification phenomena [23]. Although the relationship between economic carrying capacity, population density and land degradation is controversial and sometimes rejected by experiences in rural areas of low-income countries, it is in doubt that in desertified land may increase the proportion of people unable to maintain their living standard [21]. The eroding environment therefore does not remain a problem of the population living there, but spreads to other parts of the country, and also might reach neighbouring countries, in a process able to disseminate poverty and accelerate inequality that may lead to social conflicts, e.g. for primary resources (water in primis). 


\section{Demographic and economic indicators of land degradation: a multidimensional evaluation}

We have chosen a data set composed by 12 active and 3 supplementary indicators (see Table 2 for details); all the variables describe aspects of demography, economy, and the agriculture context, according to the logical framework shown in Figure 1. Statistical sources of such variables include National Censuses of Agriculture, Industry and Households carried out by the National Institute of Statistics as well as national accounting data [26]. They were calculated on a regional basis, for 377 municipalities of Latium (central Italy), a region featured a medium level of desertification risk [27] but with a complex spatial configuration able to provoke land degradation [19]. Such variables are candidate to be used in a complex evaluation of Environmental Sensitive Areas by the integration with climatic, soil, and vegetation variables [15].

Table 2. Variables used in the PCA (supplementary variables are reported in italics).

\begin{tabular}{lc}
\hline \multicolumn{1}{c}{ Variable } & Source \\
\hline $\begin{array}{l}\text { Population Density (DEN) } \\
\text { Demographic variation (\%) between 1991 and 2001 (VAR) } \\
\text { Elderly index (VEC) }\end{array}$ & $\begin{array}{c}\text { National Census of Households } \\
(2001)\end{array}$ \\
\hline $\begin{array}{l}\text { Density of factories (DUL) } \\
\text { Non-standard workers (\%) (PRE) }\end{array}$ & $\begin{array}{c}\text { National Census of Industry and } \\
\text { Services (2001) }\end{array}$ \\
Voluntary workers (\%) (VOL) & \\
Agricultural surface of farms with payed workers (\%) (SAL) & \\
Agricultural surface in affittance (\%) (AFF) & Ngricultural Intensity Index (INT) \\
Farm size diversity index (DIV) & (ISTAT 2000) \\
Density of tractors (TRA) & \\
Farms using agriculture machines (\%) (MEC) & \\
\hline Gross Domestic Product (pro-capita, PRO) & National Accounting Data \\
\hline Agricultural utilised area per farm (SAU) & National Census of Agriculture \\
Agricultural utilised area/Total farm area (SAT) & (2000) \\
\hline
\end{tabular}

Such analysis has therefore the aim: (i) to submit the dataset to an ESA procedure by the analysis of correlation and redundancy of variables, (i) to give an interpretation of latent patterns by multivariate analysis (also using supplementary - non active variables able to explain the significance of each axis extracted), and (iii) to assess the contribution of each variable to the final model. Finally, we used Principal Component Analysis (PCA) results to produce a spatial evaluation of the municipalities where the level of human pressure may produce higher risk conditions.

Both the Kaiser-Meyer-Olkin measure of sampling adequacy, which tests whether the partial correlations among variables are small (0.79) and Bartlett's test of sphericity, which tests whether the correlation matrix is an identity matrix $\left(\chi^{2}=1629\right.$, $\mathrm{df}=109, p<$ 0.0001 ), indicate that the factor model is appropriate to analyse our data. We have therefore subjected the data-set to PCA extracting the first two axes which explain $44 \%$ of the total variance. The number of significant axes was chosen according to the inspection of the screen-plot. The plot of factor loadings on the first two axes (Fig. 3) indicates that INT, DIV, and MEC are strictly associated to the first factor which explains about $26 \%$ of the total variance; AFF and DUL are associated to the second factor which explains about $18 \%$ of the total variance. The other variables are roundly associated to the first factor with the exception of VOL and PRE, which are very poorly associated to both factors. 
By considering the three supplementary variables (i.e., PIL, SAU, SAT), we may account for the first axis as a gradient of human pressure (high population density and demographic variations over the last ten years both correlated to the first component) associated to the intensity of land use in agriculture (SAT). Notably, both demographic and agriculture variables give a consistent contribution to the first axis, whereas the variables describing employment conditions as well as the economic structure are of rather no influence. The coordinate of each case (i.e., municipality) along the first axis may reproduce a degree of environmental degradation with negative values associated to situations of higher risks (Fig. 4). Such situation is typical of coastal municipalities featuring high population density, seasonal touristic concentration, and intensification of agriculture due to irrigation and mechanisation. These factors lead to high seasonal water use, land consumption, fire risks, soil salinization, and other causes accelerating desertification processes. As a matter of fact, in Latium higher negative values were observed in coastal municipalities, in the metropolitan area around Rome, as well as along the river Sacco valley in Frosinone province, an area characterised by a high degree of agricultural intensification [19].

All the candidate variables, with the exception of those describing the job market (PRE, VOL), both poorly contributing to the PCA main axes, may be introduced in ESA procedures to assess the level of desertification risk. The association of each variable with the concept of desertification could be assessed by exploring PCA factor loadings. For example, INT, DIV, and MEC are negatively associated to the first axis which was interpreted as a degree of environmental degradation: an increase of INT, DIV, and MEC may be directly linked to increase in land vulnerability.

Therefore, taken the coordinate of each municipality on the first PCA factor may be regarded as a measure of environmental vulnerability (i.e. lower values indicate higher risk conditions). Such value is positively correlated with non-social variables used in the same region as key descriptors of desertification risk (e.g., rainfall rate, aridity index, available water capacity of the soil), thus suggesting spatial relationships between the 'social features' and the 'ecological traits' of local configurations [19].

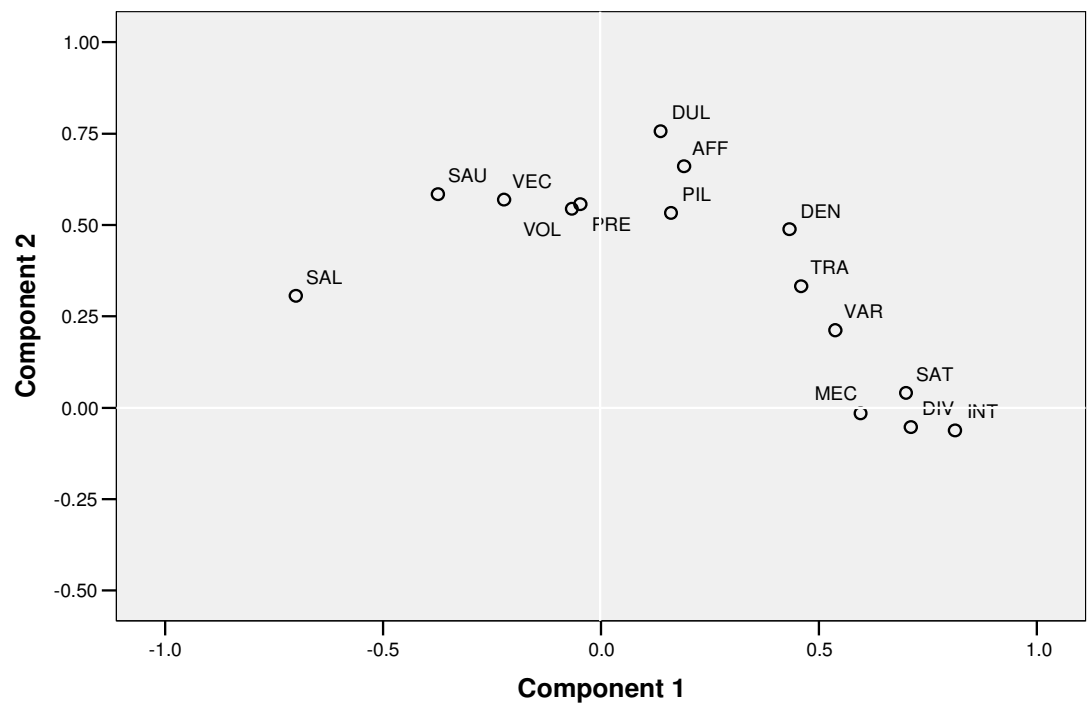

Figure 3. Plot of factor loadings (Varimax rotation) on the first two axes of the PCA performed on active and supplementary variables. 
Finally, the coordinates of each municipality in the first PCA factor taken as a measure of vulnerability to land degradation were compared to a synthetic index of desertification risk (ISD) [27]. Such index describes climate, soil, and vegetation conditions through the aggregation of eleven standardized indicators. According to ESA procedure, the geometric mean of such indicators provides a synthetic measure: higher figures indicate higher risk level and thus higher land vulnerability. Taking the year 2000 as a reference, ISD was calculated for each municipality in the Latium region [10] and compared to the vulnerability index obtained by the PCA procedure (see Figure 4). As expected, the relationship between the two indexes shows a strong positive correlation (Spearman Rank Correlation Test, $r_{\mathrm{s}}=0.72, p<0.0001, \mathrm{n}=377$ ), indicating that the PCA procedure based on social indicators may produce a sound indication of vulnerability at the local scale compared to standard indexes of desertification risk based on ecological and geo-physical indicators.

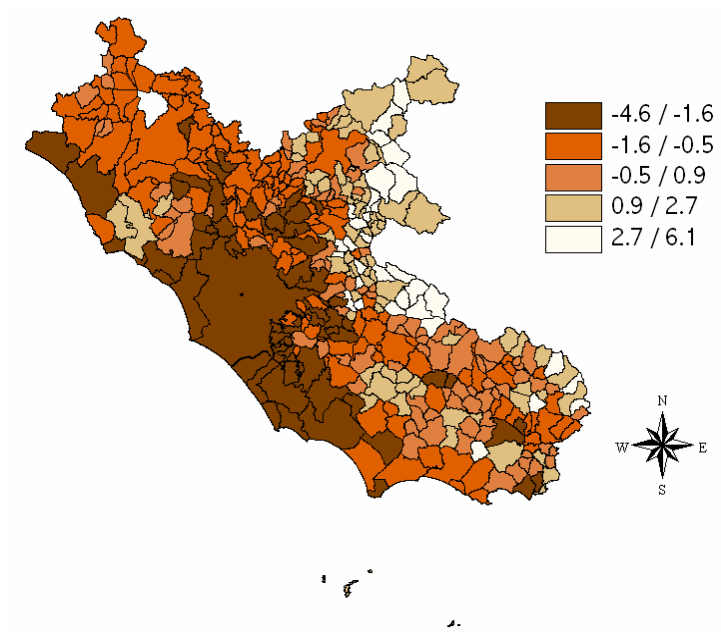

Figure 4. Map of the municipalities of Latium displaying the coordinate of each commune in the first factor of PCA (see text for details).

\section{Conclusion}

To identify the socio-economic indicators as reliable inputs for decision making and for the implementation of strategies to combat desertification is necessary to establish links of causality within these processes. The main actions useful in this assessment include: (i) the analysis of sociological and statistical methods to explore the causes and consequences of economic and social processes of desertification; (ii) the set up of metadata collection and data warehouses including a collection of multivariate tools able to analyse complex datasets (e.g., data mining, neural networks); and (iii) the definition of the correct geographic scale (e.g., census section, municipality, province) to recognise social and economic indicators [9].

An integrated evaluation of ecological and social aspects of land configuration in order to assess desertification risk should be carried out through a multi-temporal approach, taking into account the structural changes occurred during the last fifty years in southern Europe (e.g., littoralisation and industrialisation during '50 and '60 years, mechanisation and irrigation of the agriculture during ' 60 and ' 70 years, baby boom and 
higher population pressure up to ' 70 years, touristic pressure from ' 70 to ' 90 years, change in the labour marked from '90 years to 2000).

Using suitable indicators collected from long time series, a multitemporal approach may better indicate the spatial and temporal direction of desertification phenomena [9]. Giving precise spatial information on the speed of land degradation and on variation in its anthropogenic causes may represent a kin tool to drive political actions able to effectively mitigate processes of desertification at a local scale [15].

Moreover, considering a wider number of 'social' variables in the cartographic evaluation of desertification risk (e.g. population, industry, agriculture, tourism) may therefore shade new light in depicting sensitive and vulnerable areas at high spatial resolution, indicating also possible directions taken by the degradation phenomenon, as human pressure and social changes may act more rapidly than changes in climate regimes or variation in soil or vegetation composition.

Acknowledgements. We are grateful to Dr. L. Perini (CRA-UCEA, Rome) and M.E. Venezian-Scarascia (ITAL-ICID, Rome) for continuous assistance and friendship. Prof. L.M. Solivetti (University of Rome 'La Sapienza') made a critical reading of the manuscript providing a lot of useful suggestion.

\section{REFERENCES}

[1] Thornes, J.B., Brandt, J. (1995): Mediterranean desertification and land use. - John Wiley \& Sons, Chichester, UK.

[2] United Nations (1977): Desertification: its causes and consequences. - Pergamon Press, Oxford, UK.

[3] Incerti, G., Feoli, E., Giovacchini, A., Salvati, L., Brunetti, A. (2007 in press): Analysis of bioclimatic time series and their neural network-based classification to characterize drought risk patterns in south Italy. - Int. J. Biometeorology

[4] Salvati, L., Macculi, F., Zitti, M., Toscano, S. (2007 in press): Comparing indexes of intensive agricolture for the assessment of land degradation. - Biota.

[5] Brouwer, F.B., Thomas, A.J., Chadwick, M.J. (Eds.) (1991): Land use changes in Europe. Processes of change, environmental transformations and future patterns. - Kluwer Academic Publishers, Dordrecht, The Netherlands.

[6] Kosmas, C., Kirkby, M., Geeson, N. (1999): The MEDALUS project. Mediterranean desertification and land use. - Manual on key indicators of Desertification and mapping environmental sensitive areas to desertification. EUR 18882, Bruxelles, Belgium.

[7] Herrmann, S.M., Hutchinson, C.F. (2005): The changing contexts of the desertification debate. - J. Arid Env. 63: 538-555.

[8] Brandt, J., Geeson, N., Imeson, A. (2003): A desertification indicator system for Mediterranean Europe. - DESERTLINKS Project, UK.

[9] Rubio, J.L., Bochet, E. (1998): Desertification indicators as diagnosis criteria for desertification risk assessment in Europe. - J. Arid Environm. 39: 113-120.

[10] Salvati, L., Ceccarelli, T., Perini, L. (2006): Sostenibilità dell'agricoltura, fattori di pressione e fenomeni di desertificazione in Italia - Vulnerabilità ambientale nello scenario del cambiamento climatico: un'analisi a livello comunale. - CRA-Ufficio Centrale di Ecologia Agraria, Collana Climagri n. 53, Roma.

[11] Grove, A.T., Rackham, O. (1996): Physical, biological and human aspects of environmental change. - Medalus II. Final Report. Medalus Office, Berkshire, UK.

[12] Blaikie, P., Brookfield, H.C. (1987): Land degradation and society. - Methuen, London.

[13] Tanrivermis, H. (2003): Agricultural land use change and sustainable use of land resources in the Mediterranean region of Turkey. - J. Arid Env. 54: 553-564. 
[14] Brouwer, F., Crabtree, B. (1998): Environmental indicators and agricultural policy. CABI Publishing, Oxon, UK.

[15] Ceccarelli, T., Giordano, F., Luise, A., Perini, L., Salvati, L. (2006): La vulnerabilità desertificazione in Italia: raccolta, analisi, confronto e verifica delle procedure cartografiche di mappatura e degli indicatori a scala nazionale e locale. - Manuali e Linee Guida APAT, n. 40, Roma.

[16] Salvati, L., Petitta, M., Ceccarelli, T., Perini, L., Di Battista, F., Venezian-Scarascia, M.E. (2007): Italy's available water resources as estimated on the basis of the monthly water balance. - Irrig. And Drain., in press.

[17] Salvati, L., Libertà, A., Brunetti, A. (2005): Bioclimatic evaluation of drought severity: a computational approach using dry spells. - Biota 5: 55-65.

[18] Basso, F., Bove, E., Dumontet, S., Ferrara, A., Pisante, M., Quaranta, G., Taberner, M. (2000): Evaluating environmental sensitivity at the basin scale through the use of geographic information systems and remotely sensed data: an example covering the Agri basin - Southern Italy. - Catena 40: 19-35.

[19] Salvati, L., Ceccarelli, T., Brunetti, A. (2005): Agriculture and desertification processes in Italy: agro-environmental indicators for the assessment of land vulnerability. - CRACentral Office for Crop Ecology, Rome.

[20] Garcia Latorre, J., Garcia-Latorre, J., Sanchez-Picon, A. (2001): Dealing with aridity: socio-economic structures and environmental changes in an arid Mediterranean region. Land Use Policy 18: 53-64.

[21] Knerr, B. (1998): Impact of labour migration on the sustainability of agricultural development in arid regions. - In: Clarke J., Noin D. Population and environment in arid regions (Man and Biosphere Series 19). UNESCO, New York.

[22] Arnalds, O. (1997): Desertification: an appeal for a broader perspective, pp. 5-16. - In: Arnalds O., Archer S. (Eds.) Rangeland Desertification. Kluwer Academic Publishers, Dordrecht, The Netherlands.

[23] Cuffaro, N. (2001): Population, economic growth and agriculture in less developed countries. - Routledge, New York, USA.

[24] Venezian Scarascia, M.E., Di Battista, F., Salvati, L. (2006): Water resources in Italy: availability and agricultural uses. - Irrig. and Drain. 55: 115-127.

[25] Goria, A. (2000): Desertification and migration in the Mediterranean: an analytical framework, pp. 207-223 - In: Enne G., Zucca C. 2000. Desertification indicators for the European Mediterranean region. State of the art and possible methodological approaches. - Agenzia Nazionale per la Protezione dell'Ambiente, Rome, Italy.

[26] RUR, 2004. La ricchezza del territorio italiano - rapporto 2003. - Franco Angeli, Milano.

[27] Salvati, L., Ceccarelli, T., Brunetti, A. (2005): Geodatabase sul rischio di desertificazione in Italia. - CRA-Ufficio Centrale di Ecologia Agraria, Roma. 